\title{
Relación entre Movimientos Sociales y Estado en los Bachilleratos Populares
}

\author{
Juan Uriel Idalgo ${ }^{1}$ \\ Universidad Nacional de La Matanza
}

\section{Aporte de estudiante}

Resumen: Este trabajo tiene como finalidad indagar sobre la relación entre los movimientos sociales y el Estado en la implementación de políticas públicas. Partiendo de esta premisa, centraremos el análisis en torno a las intervenciones de ambos actores en la organización de bachilleratos populares. Los bachilleratos populares se diferencian de otros sistemas de escolarización por el hecho de intentar formar estudiantes como sujetos políticos (Cabrera y Brusilovsky, 2014). Estas escuelas alternativas han sido promovidas tanto por movimientos sociales, emergentes de la crisis del Estado neoliberal, como por el Estado posneoliberal. La exclusión del mercado laboral de ciertos sectores posicionó al Estado como promotor de una política que involucró a ciertos movimientos sociales en su implementación; y, por otra parte, los movimientos sociales han sido iniciadores de esta práctica educativa, con una orientación contra-hegemónica. En torno a estas relaciones surgen cuestiones sobresalientes: la expresión de una educación popular como una alternativa a la escuela tradicional, las diversas concepciones de gestión que presentan ambos actores y el involucramiento de la sociedad civil en la resolución de una problemática social expresada por diversos canales de participación.

Palabras clave: estado; movimientos sociales; participación ciudadana; democracia.

\section{Recorrido de la cuestión: entre tensiones y cooperación}

En torno a la relación entre el Estado y los movimientos sociales en la implementación de políticas públicas, podríamos caracterizar dos perspectivas de análisis. Por un lado, se han planteado las relaciones como tensiones propias de una lucha política por el reconocimiento de diversos derechos $y$, por el otro, la cooperación entre los actores analizados en la formulación e implementación de políticas públicas.

Dentro de la primera línea podemos colocar a Mirza (2006) quien sostiene que, si bien existe la negociación y el diálogo, el Estado posee omnipresencia política e institucional y

\footnotetext{
1 Estudiante de la Licenciatura en Ciencia Política, Departamento de Derecho y Ciencia Política, Universidad Nacional de La Matanza. Correo electrónico: idalgojuan88@gmail.com
} 
medios coercitivos, tales como la criminalización de la lucha y la capacidad de coerción, para cooptar o reprimir a las organizaciones sociales.

Sverdlick y Costas (2007) sostienen que los planes asistencialistas del neoliberalismo terminaron posicionando a los movimientos sociales en un espacio de funcionalidad para con las políticas gubernamentales. En referencia al surgimiento de los bachilleratos populares, ellos parece haber emergido como movimientos de reacción frente a un Estado ausente, con una orientación del reclamo hacia políticas públicas específicas. Las manifestaciones políticas de los movimientos sociales, entonces, se conciben como una construcción alternativa de participación y democracia.

Rojas (2016) sostiene que las tensiones giran en torno a la institucionalización de las prácticas educativas de los movimientos sociales, las cuales proponen la autogestión y el reconocimiento oficial, al tiempo que rechazan la hegemonía pedagógica y la gestión estatal.

Por otra parte, hay trabajos que plantean una cooperación entre ambos actores. Chac (2008) realiza un análisis de esta relación desde el tópico de la doble dimensión de las políticas públicas, es decir, desde un enfoque top down (arriba-abajo) y bottom up (abajoarriba). Argumenta que los movimientos sociales han recobrado su importancia en el terreno público en cuanto han esgrimido demandas hacia el Estado que no han podido ser desoídas.

Retamozo (2011), en tanto, destaca el trabajo conjunto de las organizaciones y el Estado en el período posneoliberal, en el cual se nota un avance en materia de participación de los movimientos sociales aunque estos se halle vinculados al signo político. El autor entiende a la relación como un conjunto de estrategias para elaborar un programa de acción y un sentido de identidad desde los intereses de los movimientos sociales.

\section{Una relación en el marco de una participación concomitante con la democracia}

Oszlak y O’Donnell (1981) conciben a las políticas públicas como acciones y omisiones del Estado frente a una cuestión que suscita el interés de otros actores de la sociedad civil. El Estado ha negado el reconocimiento oficial de ciertos bachilleratos, ha reconocido a otros y ha creado algunos por propia iniciativa: el Plan FinEs, a través de CENS, es un ejemplo de este último caso.

Fernández (2006), sobre los enfoques top down y bootom up, concibe a las acciones estatales como un proceso que surge desde arriba o como otro que surge desde abajo. La dimensión "desde abajo" nos resulta útil en tanto nos permite explicar la institucionalización e incluso la creación por parte del Estado de algunos bachilleratos en respuesta a la creciente demanda popular en torno a alternativas educativas. 
El Estado es poseedor de un doble carácter, es decir, es articulador tanto de las instituciones como de las relaciones sociales (Oszlak, 1978). De esta manera el Estado impone las estructuras sociales y el control ideológico, lo que lo lleva a oficializar o rechazar cuestiones socialmente problematizadas dependiendo de dónde surjan y del interés que representen.

Abal Medina (2010) sostiene que el Estado formulará políticas públicas acordes al modelo de desarrollo que sostenga. El período neoliberal se caracterizó por una falta de comunicación entre los actores en cuestión. La crisis de 2001 permitió la visibilización de los sectores populares excluidos y los movimientos sociales ingresaron en la escena como portadores de una crítica ante el Estado.

La crisis y la necesidad de formar sujetos políticos activos e influyentes en la realidad social, llevó a los movimientos sociales a protagonizar reclamos, a instituir estas sedes educativas y a presentarse directamente como una alternativa a la gestión estatal. La demanda principal se orientó, en principio, a la disposición de subsidios para el mantenimiento infraestructural y los salarios docentes, así como también hacia la oficialización sus dinámicas de enseñanza, bregando por la posibilidad de otorgar certificaciones a los alumnos que estudiaran y que se egresaran en estos ámbitos (Caisso, 2014).

Para Amatya Sen (citado en Tonon, 2015), la democracia es el único sistema que permite la libertad de agencia de cada persona en la esfera social y comunitaria. Es importante comprender que sólo en un régimen de organización democrática podemos asistir a esta relación entre movimientos sociales y Estado, más allá de las tensiones y conflictos, la misma sería inexistente en un régimen que limitara las libertades de asociación.

Concebimos a la democracia en relación directa con el ejercicio de la ciudadanía. Por lo tanto coincidimos con Tonon (2008) cuando sostiene que la ciudadanía debe considerarse más allá del status legal. La ciudadanía puede rastrearse en los movimientos sociales y sus actividades educativas, pues son elementos portadores de una identidad propia sostenida en un sentido de pertenencia que promueve la solidaridad colectiva y una cultura política.

Las interpelaciones que los movimientos sociales realizan al Estado, en palabras de Smulovitz (citado en Tonon, 2008), pueden caracterizarse como parte de un proceso de construcción que depende de la puesta en práctica de la ciudadanía y es resultante de una lucha política, en este caso, por el derecho a la educación.

\section{Conclusión}

Consideramos que los posicionamientos políticos y los modelos de desarrollos influyen en la relación entre Estado y movimientos sociales. En el período posneoliberal del 
2003, el modelo de desarrollo promovió diversas políticas sociales a través de la participación de movimientos sociales encolumnados tras el oficialismo. Sin embargo, también hubo tensiones con movimientos opositores y una tendencia al clientelismo. Las orientaciones políticas de los movimientos sociales y sus capacidades de negociación frente al Estado parecen ser algunas de las claves que explican la relación pragmática con el sector público.

Valoramos la participación ciudadana de los movimientos en la resolución de problemáticas sociales, pues la misma surge desde las libertades inherentes a los regímenes democráticos aportando nuevas concepciones de gestión y promoviendo una cultura política. Los nuevos canales de participación y la cooperación entre actores refuerzan la democracia a la vez que sólo son posibles a través de ella.

\section{Referencias bibliográficas}

Abal Medina, J. M. (2010). La reforma del Estado y el fortalecimiento de las instituciones públicas. En P. Amaya (Comp.), El Estado y las Politicas Públicas en América Latina: Avances y desafíos de un continente que camina en el fortalecimiento de la inclusión social (pp. 17-36). La Plata: Universitaria de La Plata.

Cabrera, M., Brusilovsky, S. (2014). Bachilleratos Populares. Los objetivos y el colectivo docente de una propuesta de educación popular escolar. Polifonías- Revista de Educación, Año III (5), 42-73.

Chac, M. (2008). Gobernanza y participación ciudadana en las políticas públicas frente al reto del desarrollo. México: Universidad Autónoma Metropolitana-Xochimilco.

Fernández, A. (1996). Políticas Públicas. En M. Caminal Badia (Ed), Manual de Ciencia Política (pp. 495-517). Madrid: Editorial Tecnos.

Mirza, C. (2006). Movimientos sociales y sistemas políticos en América Latina: La construcción de nuevas democracias. Programa regional de becas CLACSO. Buenos Aires. Disponible en: http://www.clacso.org.ar/biblioteca.

Oszlak, O. (1978). Formación histórica del Estado en América Latina: Elementos teoricometodologicos para su estudio. CEDES, 1 (3).

Oszlak, O. y O’Donnell, G. (1981). Estado y políticas estatales en América Latina: hacia una estrategia de investigación. Centro de Estudios de Estado y Sociedad (CEDES), Documento G.E. CLACSO/№4.

Retamozo, M. (2011). Movimientos sociales, política y hegemonía en Argentina. Polis Revista de la Universidad Bolivariana, 10 (28), 243-279. 
Rojas, D. (2016). Bachilleratos Populares en Buenos Aires. Repensando la relación entre Movimientos sociales, educación popular y Estado. Tesis de posgrado. Universidad de la Republica, Facultad de Ciencias Sociales. Montevideo, Uruguay.

Sverdlick, I. y Costas, P. (2007). Bachilleratos Populares en Empresas Recuperadas y Organizaciones Sociales: La actuación de los movimientos y organizaciones sociales. Laboratorio de Políticas Públicas, Serie de ensayos e investigaciones (30), 2-65.

Tonon, G. (2008). La Universidad como escenario de construcción de ciudadanía: percepciones de jóvenes estudiantes de la carrera de Ciencia Política. En O. Roldán Vargas (Comp.), Niñez y juventud latinoamericanas: experiencias de relacionamiento y acción colectiva (pp. 51-72). Medellín: CINDE.

Tonon, G. (2015). Los Sujetos como protagonistas de las políticas de bienestar: una reflexión desde la calidad de vida y las human capabilities. En Primer Foro Internacional de Bienestar y Desarrollo: El bienestar subjetivo. Un cambio paradigmático en la noción del progreso y en el diseño de políticas públicas. Jalisco, México: Gobierno del Estado de Jalisco y Grupo Planeta.

\section{Otro documento consultado}

Caisso. L. (2014). “¡Ojalá seamos un colegio y tengamos aulas!”. Demandas educativas y participación política estudiantil en un Bachillerato Popular. Actas de las Jornadas sobre Etnografía y Procesos Educativos. Córdoba, Argentina, 11 y 12 de septiembre, 1-20. 